\title{
Association between food insecurity and access to a mental health professional: cross-sectional analysis of NHANES 2007- 2014
}

Nina Camille Burruss ${ }^{1,2}$, Marina Girgis ${ }^{1,3}$, Karen Elizabeth Green ${ }^{4}$, Lingyi Lu ${ }^{5}$ and Deepak Palakshappa ${ }^{5,6^{*}}$

\begin{abstract}
Background: To determine if individuals with food insecurity (FI) were less likely to have seen a mental health professional (MHP) within the past year than individuals without Fl.

Methods: This is a cross-sectional analysis of data from the National Health and Nutrition Examination Survey (NHANES) conducted in the United States between 2007 and 2014. All participants 20 years of age or older were eligible for this study. We excluded participants who were pregnant, missing FI data, or missing data from the Patient Health Questionnaire (PHQ-9). The primary outcome was self-reported contact with a MHP in the past 12 months. We used multivariable logistic regression models to test the association between $\mathrm{Fl}$ and contact with a MHP, controlling for all demographic and clinical covariates.

Results: Of the 19,789 participants, 13.9\% were food insecure and $8.1 \%$ had major depressive disorder (MDD). In bivariate analysis, participants with FI were significantly more likely to have MDD $(5.3 \%$ vs $2.8 \%, p<0.0001)$ and to have been seen by a MHP in the preceding 12 months (14.0\% vs $6.9 \%, p<0.0001)$. In multivariable models, adults with $\mathrm{Fl}$ had higher odds of having seen a MHP $(\mathrm{OR}=1.32$, Cl: 1.07, 1.64).

Conclusions: This study demonstrates that individuals with FI were significantly more likely to have seen a MHP in the preceding 12 months compared to individuals without Fl. Given the growing interest in addressing unmet social needs in healthcare settings, this data suggests that visits with MHPs may be a valuable opportunity to screen for and intervene on Fl.
\end{abstract}

Keywords: Food insecurity, Mental health professional, Depression, Social determinants of health, NHANES

\section{Background}

Food insecurity (FI), defined by the United States Department of Agriculture (USDA) as inconsistent access to food due to social or economic constraints that limit intake and nutrition, is a major public health

\footnotetext{
* Correspondence: dpalaksh@wakehealth.edu

${ }^{5}$ Division of Public Health Sciences, Wake Forest School of Medicine, Winston-Salem, NC, USA

${ }^{6}$ Departments of Internal Medicine and Pediatrics, Wake Forest School of Medicine, Medical Center Blvd, Winston-Salem, NC 27157, USA

Full list of author information is available at the end of the article
}

problem in the United States (U.S.) [1]. Prior to the COVID-19 pandemic, 10.5\% of U.S. households, or over 35 million Americans, were food insecure at some point during 2019 [2]. Although the exact number is still unknown, it is estimated that an additional 17 million people in the U.S. will likely be food insecure due to the economic impact of the COVID-19 pandemic. Various factors including, but not limited to, mental health, income, employment, and race/ethnicity, are risk factors that have been shown to impact individuals' and households' access to food [3-6].

(C) The Author(s). 2021 Open Access This article is licensed under a Creative Commons Attribution 4.0 International License, which permits use, sharing, adaptation, distribution and reproduction in any medium or format, as long as you give appropriate credit to the original author(s) and the source, provide a link to the Creative Commons licence, and indicate if changes were made. The images or other third party material in this article are included in the article's Creative Commons licence, unless indicated otherwise in a credit line to the material. If material is not included in the article's Creative Commons licence and your intended use is not permitted by statutory regulation or exceeds the permitted use, you will need to obtain permission directly from the copyright holder. To view a copy of this licence, visit http://creativecommons.org/licenses/by/4.0/. The Creative Commons Public Domain Dedication waiver (http://creativecommons.org/publicdomain/zero/1.0/) applies to the data made available in this article, unless otherwise stated in a credit line to the data. 
Individuals living in a food insecure household are at higher risk of worse health outcomes, and there is a well-documented relationship between FI and mental health conditions, particularly depression [3-6]. The association between FI and depressive symptoms is thought to be bidirectional [7]. Individuals with mental illnesses, such as major depressive disorder (MDD), may be more likely to experience FI because they are less likely to work or to access food and other supportive resources due to their depressive symptoms. Conversely, FI is thought to be an independent risk factor for the development of mental illness even when controlling for socioeconomic status [6]. Because of the increased psychological stressors associated with difficulty securing adequate nutrition, adults who are food insecure may develop mental illness, and there is a positive correlation between worsening FI and the number of reported depressive symptoms $[5,8]$.

Additionally, FI has also been associated with worse patterns of healthcare use, including delays in seeking necessary medical care. Individuals in food insecure households are less likely to report a usual source of care and more likely to postpone necessary preventative medical care due to competing demands; for example, individuals have to choose between spending money on food versus medical care $[9,10]$. FI has also been associated with increased acute care utilization and total healthcare expenditures [10, 11]. Additionally, multiple studies have shown that individuals with MDD, regardless of food security status, are more likely to interact with healthcare professionals than individuals without MDD [9, 12]. The relationships between FI, preventative care, and acute care have been established, however, there is less information regarding the association between FI and mental healthcare utilization [13].

Although the relationship between FI and MDD has been established, there is limited data on the association between FI and access to a mental health professional (MHP). To fill this gap in the literature, our primary goal was to determine if individuals living in a food insecure household were more likely to have seen a MHP in the prior 12 months than individuals who did not live in a food insecure household.

\section{Methods}

\section{Study design and data sources}

We conducted a pooled cross-sectional analysis of the 2007-2014 National Health and Nutrition Examination Survey (NHANES). The National Center for Health Statistics conducts NHANES, which is a series of large, crosssectional surveys. Participants in NHANES undergo an inhome interview on a variety of demographic and health characteristics, a physical examination conducted at a mobile examination center, and laboratory measurements.
Results of NHANES are weighted to represent the noninstitutionalized U.S. population. Further details of the study design and procedures have been previously published [14]. For this study, we combined data from the 2007-2008, 2009-2010, 2011-2012, and 2013-2014 waves of NHANES.

\section{Study sample}

All participants who were 20 years of age or older were eligible to be included in this study (unweighted $N=23$, $482)$. We excluded participants who were pregnant $(N=$ $247)$, missing FI data $(N=228)$, or missing data on the patient health questionnaire (PHQ-9; $N=3218$ ) for a total unweighted sample size of 19,789. The total weighted sample size used for this study was 608,437 , 356.

\section{Outcome}

Our primary outcome was contact with a MHP in the past 12 months (yes or no). All respondents are asked "During the past 12 months, have you seen or talked to a mental health professional such as a psychologist, psychiatrist, psychiatric nurse, or clinical social worker about your health?" and our outcome was based on selfreport to this question.

\section{Exposure}

Our exposure of interest was household FI. FI was measured in NHANES using the 18-item Food Security Survey Module [15]. This validated questionnaire was developed by the USDA to measure household FI over the prior 12 months. NHANES administers the Food Security Survey Module in accordance with the USDA recommendations and uses the established scoring system for responses to the items. Households are categorized as having high food security ( 0 affirmative response), marginal food security (1-2 affirmative responses), low food security (3-7 affirmative responses), and very low food security ( $\geq 8$ affirmative responses). Consistent with USDA definitions, we categorized participants with low or very low food security as food insecure, and we analyzed FI as a binary variable for this study (food secure: 0-2 affirmative responses; food insecure: $\geq 3$ affirmative responses). Sensitivity analyses evaluating FI as a 4-category variable found similar results (data not shown).

\section{Covariates}

Based on prior studies, our covariates included demographic and clinical characteristics that have been associated with FI and/or care by a MHP $[2,5,16]$. These included age, gender, race/ethnicity (non-hispanic White, non-hispanic Black, Hispanic, or other), and birthplace (U.S. or not). We also included marital status, highest 
educational level achieved ( $<$ high school, graduated high school, or $>$ high school), household income-to-poverty ratio, health insurance (private, Medicare, public not including Medicare, or none), smoking status (current, former, or never), and if a participant reported using a nutrition assistance program (including Supplemental Nutrition Assistance Program (SNAP), Special Supplemental Nutrition Assistance Program for Women, Children, and Infants (WIC), or received food from a food pantry or soup kitchen).

We also included medical comorbidities including diabetes, dyslipidemia, hypertension, cardiovascular disease, and MDD. Consistent with prior studies using NHANES data [17-19], we categorized diabetes, dyslipidemia, and hypertension based on questionnaire, physical examination, and laboratory data. A participant was defined as having diabetes if they had any of the following: selfreport of diabetes, glycated hemoglobin $>6.5 \%$, fasting glucose $>126$, or currently taking a diabetes medication (including sulfonylurea, insulin, or an incretin mimetic). Dyslipidemia was defined as having any of the following: self-report of high cholesterol, currently taking a cholesterol lowering medication, or laboratory diagnosis of dyslipidemia (total cholesterol $\geq 240 \mathrm{mg} / \mathrm{dl}$, $\mathrm{HDL}<30$ $\mathrm{mg} / \mathrm{dl}$, LDL $\geq 160 \mathrm{mg} / \mathrm{dl}$, Triglycerides $\geq 150 \mathrm{mg} / \mathrm{dl}$ ). Hypertension was defined as any of the following: selfreport of high blood pressure, currently taking a blood pressure medication, or elevated blood pressure based on the average of 3 blood pressure readings (Systolic Blood Pressure $>140 \mathrm{mmHg}$ or Diastolic Blood pressure $>90 \mathrm{mmHg}$ ). Cardiovascular disease was determined by self-report of a history of coronary artery disease, angina, prior myocardial infarction, congestive heart failure, or stroke.

MDD was determined by responses to the PHQ-9 [20, 21]. The PHQ-9 consists of nine items that assess the frequency of depressive symptoms over the prior 2 weeks. Questions include how often over the last 2 weeks have you felt down or depressed and how often have you had thoughts that you would be better off dead or hurting yourself in some way. Responses include "not at all", "several days", "more than half the days", and "nearly every day" and are given a point ranging from 0 to 3. We categorized participants as having MDD (yes or no) if they had a score of $\geq 10$ on the PHQ-9 [20, 21].

\section{Statistical analysis}

Participant characteristics were presented as means (standard deviation) for continuous variables or $\mathrm{N}$ (percent) for categorical variables. We performed bivariate analyses testing the association between FI, contact with a MHP, and all individual covariates using t-tests or chisquare test. We used multivariable logistic regression models to test the association between FI and contact with a MHP, controlling for all demographic and clinical covariates. A priori, we hypothesized MDD as a possible effect modifier. We did not find a significant interaction term, so we treated MDD as a confounder. We also evaluated for significant differences in the association between FI and contact with a MHP based on participant characteristics (age, gender, race/ethnicity, marital status, highest education level achieved, birthplace, health insurance, and medical comorbidities). For participant characteristics with a potentially significant interaction $(p<0.2)$, we used predictive margins to determine the adjusted proportion who reported contact with a MHP. All analyses accounted for the complex survey design of NHANES by applying the appropriate sample weights, clustering, and the primary sampling unit. As only a small number of participants were missing data in variables $(<8 \%)$, we used listwise deletion to account for missing data. We used a two-sided hypothesis test and considered a $p$-value of $<0.05$ statistically significant. All analyses were conducted using Stata 15.1 (StataCorp, College Station, TX). The Wake Forest School of Medicine Institutional Review Board deemed this study of publically available, de-identified data exempt from human subjects research.

\section{Results}

\section{Study population characteristics}

Of the 19,789 participants (weighted study population $N=608,437,356)$, the majority was female $(50.7 \%)$, married $(55.6 \%)$, and had greater than a high school education level (60.7\%) (Table 1). The mean age was 47.5 years $(\mathrm{SD}=16.8$ years) and the mean household incometo-poverty ratio was $3.0(\mathrm{SD}=1.7)$. We found that $8.1 \%$ of participants were identified as having MDD. Of the participants, $13.9 \%$ lived in a food insecure household with 20.6\% reporting SNAP usage, 6.5\% reporting WIC usage in the past year, and $7.1 \%$ reporting emergency food (food pantry, soup kitchen) usage.

\section{Bivariate analysis of food insecurity and covariates}

In bivariate analysis, FI was associated with younger age (mean 41.4 years vs 48.5 years), lower educational attainment $(38.4 \%$ vs $64.3 \%$ with $>$ high school education), lower household income-to-poverty ratio (mean 1.4 vs mean 3.2), birthplace outside of the U.S. (23.9\% vs $15.1 \%)$, and no health insurance $(40.6 \%$ vs $15.8 \%$ ) (all $p<0.0001$ ) (Table 2). Of the study participants, individuals with FI were more likely to have diabetes $(14.7 \%$ vs $12.2 \%, p=0.002)$ and cardiovascular disease $(9.0 \%$ vs $7.4 \% ; p=0.03)$. Food insecure participants were also more likely to have MDD (5.3\% vs $2.8 \%, p<0.0001)$. Participants who lived in a food insecure household were significantly more likely to have been seen by a MHP in the last 12 months $(14.0 \%$ vs $6.9 \%, p<0.0001)$. 
Table 1 Study population characteristics

\begin{tabular}{|c|c|c|}
\hline & $N=19,789$ (Weighted $N=608,437,356)$ & Weighted \% \\
\hline Age & Mean $=47.5(S D=16.8)$ & \\
\hline \multirow[t]{2}{*}{ Gender } & Female & 50.7 \\
\hline & Male & 49.3 \\
\hline \multirow[t]{4}{*}{ Race/ethnicity } & Non-Hispanic, White & 69.0 \\
\hline & Non-Hispanic, Black & 11.0 \\
\hline & Hispanic & 13.5 \\
\hline & Other & 6.6 \\
\hline \multirow[t]{6}{*}{ Marital status } & Married & 55.6 \\
\hline & Widowed & 5.6 \\
\hline & Divorced & 10.7 \\
\hline & Separated & 2.3 \\
\hline & Never married & 18.4 \\
\hline & Living with partner & 7.4 \\
\hline \multirow[t]{3}{*}{ Adult education level } & $<$ High school & 16.8 \\
\hline & High school graduate & 22.5 \\
\hline & >High school & 60.7 \\
\hline Household Income-to-poverty ratio & Mean $=3.0(\mathrm{SD}=1.7)$ & \\
\hline Born outside the US & Yes & 16.4 \\
\hline \multirow[t]{4}{*}{ Insurance } & Private & 49.9 \\
\hline & Medicare & 13.7 \\
\hline & Public, not Medicare & 17.2 \\
\hline & None & 19.2 \\
\hline \multirow[t]{3}{*}{ Smoking } & Never & 54.7 \\
\hline & Current & 20.7 \\
\hline & Former & 24.6 \\
\hline SNAP & Yes & 20.6 \\
\hline WIC & Yes, received in last 12 months & 6.5 \\
\hline Emergency food (food pantry, soup kitchen) & Yes & 7.1 \\
\hline Diabetes & Yes & 12.6 \\
\hline Dyslipidemia & Yes & 55.5 \\
\hline Hypertension & Yes & 38.0 \\
\hline Cardiovascular Disease & Yes & 7.7 \\
\hline MDD & Yes & 8.1 \\
\hline Food insecurity & Yes & 13.9 \\
\hline MHP & Yes & 7.9 \\
\hline
\end{tabular}

SD standard deviation, SNAP Supplemental Nutrition Assistance Program, WIC The Special Supplemental Nutrition Program of Women, Infants, and Children, MDD Major Depressive Disorder, MHP mental health provider

\section{Food insecurity and contact with a mental health professional}

We used multivariable logistic regression models to test the association between FI and contact with a MHP, controlling for all demographic and clinical covariates. Using these models, adults with FI were significantly more likely to report having had contact with a MHP in the prior 12 months than individuals living in a food secure household $(\mathrm{OR}=1.32,95 \% \mathrm{CI}: 1.07,1.64 ; p=$ 0.009) (Table 3).

We found a potential interaction $(p<0.2)$ between FI and health insurance, FI and diabetes, and FI and hypertension (Table 4). Among participants insured by Medicare, $7.32 \%$ (95\% CI: 5.02, 9.62\%) who were food secure reported contact with a MHP compared to $19.52 \%$ (95\% CI: $10.87,28.17 \%)$ with FI. FI was associated with an 
Table 2 Characteristics of food secure compared to food insecure participants

\begin{tabular}{|c|c|c|c|c|}
\hline & & Food secure (\%) & Food insecure (\%) & $p$-value \\
\hline Total population & $N=19,789$ (weighted study population $N=608,437,356$ ) & 86.1 & 13.9 & \\
\hline Age & Mean (SD) & $48.5(16.8)$ & $41.4(14.9)$ & $<0.0001$ \\
\hline \multirow[t]{3}{*}{ Gender } & & & & 0.39 \\
\hline & Male & 49.4 & 48.5 & \\
\hline & Female & 50.6 & 51.5 & \\
\hline \multirow[t]{5}{*}{ Race } & & & & $<0.0001$ \\
\hline & Non-Hispanic, White & 72.2 & 48.8 & \\
\hline & Non-Hispanic, Black & 9.7 & 18.6 & \\
\hline & Hispanic & 11.4 & 26.6 & \\
\hline & Other & 6.6 & 6.0 & \\
\hline \multirow[t]{6}{*}{ Marital status } & & & & $<0.0001$ \\
\hline & Married & 58.6 & 36.7 & \\
\hline & Widowed & 5.8 & 4.8 & \\
\hline & Divorced/separated & 11.9 & 19.7 & \\
\hline & Never married & 17.2 & 25.9 & \\
\hline & Living with partner & 6.5 & 13.0 & \\
\hline \multirow[t]{4}{*}{ Education level } & & & & $<0.0001$ \\
\hline & $<$ High school & 14.1 & 34.1 & \\
\hline & High school graduate & 21.7 & 27.5 & \\
\hline & $>$ High school & 64.3 & 38.4 & \\
\hline Income-to-poverty ratio & Mean (SD) & $3.2(1.6)$ & $1.4(1.1)$ & $<0.0001$ \\
\hline Born outside US & Yes & 15.1 & 23.9 & $<0.0001$ \\
\hline \multirow[t]{5}{*}{ Insurance } & & & & $<0.0001$ \\
\hline & Private & 53.7 & 25.7 & \\
\hline & Medicare & 14.7 & 7.7 & \\
\hline & Public, not Medicare & 15.8 & 26.1 & \\
\hline & None & 15.8 & 40.6 & \\
\hline \multirow[t]{4}{*}{ Smoking } & & & & $<0.0001$ \\
\hline & Never & 56.5 & 43.6 & \\
\hline & Current & 17.7 & 39.1 & \\
\hline & Former & 25.8 & 17.3 & \\
\hline SNAP & Yes & 4.8 & 16.7 & $<0.0001$ \\
\hline WIC & Yes & 4.2 & 2.3 & $<0.0001$ \\
\hline Emergency food & Yes & 3.4 & 30.2 & $<0.0001$ \\
\hline Diabetes & Yes & 12.2 & 14.7 & 0.002 \\
\hline Dyslipidemia & Yes & 55.9 & 53.5 & 0.10 \\
\hline Hypertension & Yes & 38.5 & 35.0 & 0.01 \\
\hline Cardiovascular Disease & Yes & 7.4 & 9.0 & 0.03 \\
\hline MDD & Yes & 6.2 & 20.4 & $<0.0001$ \\
\hline MHP & Yes & 6.9 & 14.0 & $<0.0001$ \\
\hline
\end{tabular}

SD standard deviation, SNAP Supplemental Nutrition Assistance Program, WIC The Special Supplemental Nutrition Program of Women, Infants, and Children, MDD Major Depressive Disorder, MHP mental health provider 
Table 3 Multivariable analysis: Association between food insecurity and contact with a mental health professional

\begin{tabular}{|c|c|c|c|c|}
\hline \multicolumn{2}{|l|}{ Mental Health Professional } & \multirow{2}{*}{$\begin{array}{l}\text { Odds Ratio } \\
\text { Ref }\end{array}$} & \multirow[t]{2}{*}{$95 \% \mathrm{Cl}$} & \multirow[t]{2}{*}{$p$-value } \\
\hline Food security & Secure & & & \\
\hline & Insecure & 1.32 & $1.07,1.63$ & 0.009 \\
\hline \multirow[t]{2}{*}{ MDD } & No & ref & & \\
\hline & Yes & 4.04 & $3.19,5.11$ & $<0.001$ \\
\hline Age & & 0.99 & $0.98,0.99$ & 0.001 \\
\hline \multirow[t]{2}{*}{ Gender } & Male & Ref & & \\
\hline & Female & 1.15 & $0.98,1.35$ & 0.073 \\
\hline \multirow[t]{4}{*}{ Race/ethnicity } & White & Ref & & \\
\hline & Hispanic & 0.89 & $0.73,1.08$ & 0.247 \\
\hline & Black & 0.65 & $0.52,0.80$ & $<0.001$ \\
\hline & Other & 0.71 & $0.53,0.94$ & 0.016 \\
\hline \multirow[t]{5}{*}{ Marital status } & Married & Ref & & \\
\hline & Widowed & 1.06 & $0.75,1.48$ & 0.75 \\
\hline & Divorced/separated & 1.73 & $1.35,2.21$ & $<0.001$ \\
\hline & Never married & 1.47 & $1.17,1.83$ & 0.001 \\
\hline & Living with partner & 1.12 & $0.88,1.43$ & 0.35 \\
\hline \multirow[t]{3}{*}{ Education level } & $<$ High school & Ref & & \\
\hline & High school graduate & 1.44 & $1.13,1.83$ & 0.004 \\
\hline & >High school & 2.16 & $1.73,2.69$ & $<0.001$ \\
\hline \multirow[t]{2}{*}{ Born outside US } & No & Ref & & \\
\hline & Yes & 0.77 & $0.59,0.99$ & 0.041 \\
\hline \multirow[t]{4}{*}{ Insurance } & Private & Ref & & \\
\hline & None & 0.79 & $0.61,1.02$ & 0.08 \\
\hline & Medicare & 1.36 & $0.90,2.07$ & 0.152 \\
\hline & Public, not Medicare & 2.02 & $1.62,2.52$ & $<0.001$ \\
\hline \multirow[t]{3}{*}{ Smoking } & Never & Ref & & \\
\hline & Current & 1.67 & $1.34,2.08$ & $<0.001$ \\
\hline & Former & 1.41 & $1.12,1.76$ & 0.003 \\
\hline \multirow[t]{2}{*}{ SNAP } & No & Ref & & \\
\hline & Yes & 1.36 & $1.10,1.70$ & 0.005 \\
\hline \multirow[t]{2}{*}{ WIC } & No & Ref & & \\
\hline & Yes & 0.70 & $0.52,0.94$ & 0.016 \\
\hline \multirow[t]{2}{*}{ Emergency food (food pantry, soup kitchen) } & No & Ref & & \\
\hline & Yes & 1.48 & $1.16,1.88$ & 0.002 \\
\hline Income-to-poverty ratio & & 1.04 & $0.97,1.12$ & 0.28 \\
\hline \multirow[t]{2}{*}{ DM } & No & Ref & & \\
\hline & Yes & 0.78 & $0.63,0.96$ & 0.021 \\
\hline \multirow[t]{2}{*}{ Dyslipidemia } & No & Ref & & \\
\hline & Yes & 0.88 & $0.75,1.05$ & 0.152 \\
\hline \multirow[t]{2}{*}{ HTN } & No & Ref & & \\
\hline & Yes & 1.12 & $0.91,1.39$ & 0.284 \\
\hline \multirow[t]{2}{*}{ Cardiovascular disease } & No & Ref & & \\
\hline & Yes & 1.12 & $0.82,1.54$ & 0.461 \\
\hline
\end{tabular}

We used multivariable logistic regression models to test the association between FI and contact with a MHP, controlling for all demographic and clinical covariates. Cl confidence interval, MDD major depressive disorder, SNAP Supplemental Nutrition Assistance Program, WIC The Special Supplemental Nutrition Program of Women, Infants, and Children, DM diabetes, HTN hypertension 
Table 4 Differences in Contact with a Mental Health Professional by Participant Characteristics

\begin{tabular}{|c|c|c|c|c|}
\hline & & Predicted Proportion $(95 \% \mathrm{Cl})$ & Adjusted difference $(95 \% \mathrm{Cl})$ & $p$-value \\
\hline \multicolumn{5}{|l|}{ Insurance } \\
\hline \multirow[t]{2}{*}{ None } & Food secure & $5.47 \%(4.34,6.60 \%)$ & Ref & \\
\hline & Food insecure & $7.01 \%(5.18,8.83 \%)$ & $1.72 \%(-0.39,3.84 \%)$ & 0.11 \\
\hline \multirow[t]{2}{*}{ Private } & Food secure & $6.77 \%(5.72,7.82 \%)$ & Ref & \\
\hline & Food insecure & $7.62 \%(5.54,9.70 \%)$ & $0.86 \%(-1.41,3.12 \%)$ & 0.45 \\
\hline \multirow[t]{2}{*}{ Public, not Medicare } & Food secure & $12.45 \%(10.72,14.17 \%)$ & Ref & \\
\hline & Food insecure & $14.23 \%(11.00,17.47 \%)$ & $1.94 \%(-2.08,5.96 \%)$ & 0.34 \\
\hline \multirow[t]{2}{*}{ Medicare } & Food secure & $7.32 \%(5.02,9.62 \%)$ & Ref & \\
\hline & Food insecure & $19.52 \%(10.87,28.17 \%)$ & $8.35 \%(2.69,14.00 \%)$ & 0.004 \\
\hline \multicolumn{5}{|l|}{ Diabetes } \\
\hline \multirow[t]{2}{*}{ No } & Food secure & $7.90 \%(7.15,8.66 \%)$ & Ref & \\
\hline & Food insecure & $9.51 \%(8.02,10.10 \%)$ & $1.62 \%(0.00,3.23 \%)$ & 0.05 \\
\hline \multirow[t]{2}{*}{ Yes } & Food secure & $5.65 \%(4.48,6.82 \%)$ & Ref & \\
\hline & Food insecure & $10.21 \%(7.75,12.67 \%)$ & $4.30 \%(1.85,6.75 \%)$ & 0.001 \\
\hline \multicolumn{5}{|l|}{ Hypertension } \\
\hline \multirow[t]{2}{*}{ No } & Food secure & $7.59 \%(6.76,8.41 \%)$ & Ref & \\
\hline & Food insecure & $8.45 \%(6.82,10.07 \%)$ & $0.14 \%(-1.26,1.55 \%)$ & 0.84 \\
\hline \multirow[t]{2}{*}{ Yes } & Food secure & $7.74 \%(6.49,8.98 \%)$ & Ref & \\
\hline & Food insecure & $12.00 \%(9.54,14.47 \%)$ & $4.52 \%(1.27,7.77 \%)$ & 0.007 \\
\hline
\end{tabular}

adjusted difference of $8.35 \%$ (95\% CI: 2.69, 14.00\%; $p=$ 0.004 ) among participants insured by Medicare. Among participants with diabetes, 5.65\% (95\% CI: 4.48, 6.82\%) who were food secure reported contact with a MHP compared to $10.21 \%$ (95\% CI: $7.75,12.67 \%$ ) with FI, and FI was associated with an adjusted difference of $4.30 \%$ (95\% CI: $1.85,6.75 \% ; p=0.001$ ) among participants with diabetes. Among participants with hypertension, FI was associated with an adjusted difference of $4.52 \%$ (95\% CI: 1.27, $7.77 \% ; p=0.007)$.

\section{Discussion}

Using this nationally representative U.S. sample, we demonstrate that individuals living in a food insecure household are significantly more likely to have seen a MHP in the preceding 12 months than individuals who do not live in a food insecure household. With the growing interest in addressing patients' unmet social needs as a routine part of clinical care, this data suggests that MHPs may be an important area to develop interventions to screen patients for FI and help assist patients with unmet food needs.

The social determinants of health, or the areas that people grow, work, live, and age, have a profound impact on morbidity and mortality, and the social determinants can lead to unmet health-related social needs, such as FI [22-24]. Additionally, the COVID-19 pandemic has highlighted and exacerbated many of the underlying inequities that already existed in the U.S., and the rates of FI have increased due to the economic impact of the COVID-19 pandemic. Historically, addressing patients' unmet social needs has been the focus of public health and public policy communities, but an increasing number of national U.S. healthcare organizations have recommended that health systems screen and address FI and other unmet social needs in clinical care settings to improve patient care and population health [25-27]. With these national recommendations in the U.S., there has been a growing body of evidence that addressing FI in clinical care settings can improve patients' access to food resources [28, 29]. These efforts have primarily focused on primary care specialties, including pediatrics, family medicine, and internal medicine, as areas to address patients' unmet social needs $[10,12,30]$. However, these specialties are often overburdened with screening expectations during short clinical encounters. Studies have demonstrated low screening rates for unmet health-related social needs during these visits, indicating potentially missed opportunities for intervention [31]. Further, prior studies have shown that individuals in food insecure households are less likely to present for preventative care visits, and many patients and families suffering from FI may be missed if screening programs only focused on preventative care visits $[10,11]$. Our results demonstrate that individuals living in food insecure households were significantly more likely to have contact 
with a MHP than those who were food secure in the prior 12 months, controlling for depression. This is consistent with a prior study in Canada that used national survey data to demonstrate that food insecure individuals were more likely to have contact with a designated MHP, such as a psychiatrist, and an increasing degree of FI correlated with increased odds of seeking mental healthcare treatment [13]. MHPs and mental health clinics may be an additional area to screen patients for FI with a high likelihood of identifying patients with unmet food needs. In this way, MHPs may help offset the significant screening burden placed on primary care physicians, while increasing identification of those with unmet social needs.

Although our results were consistent with a prior study in Canada, given the issues with healthcare access that individuals with FI can experience in the U.S., it was a little surprising that participants who reported FI in our study were more likely to report seeing a MHP in the prior 12 months. There are several potential reasons why we may have seen this association. First, prior studies have shown that patients with FI are more likely to have a concomitant psychiatric illness such as MDD, and individuals with psychiatric illness are more likely to see a $\operatorname{MHP}[5,7,8]$. Although we did not find a significant interaction between FI and MDD in our study, it could be that individuals' with worse mental health are more likely to be food insecure and could be why we found a significant association between FI and contact with a MHP. This could also be why we found a significant interaction between FI and if participants received Medicare insurance given that individuals with certain mental health illnesses are eligible to receive Medicare before the age of 65 years. Second, we found that the association between FI and contact with a MHP varied if participants reported having Medicare insurance, diabetes, or hypertension. As older individuals and individuals younger than 65 years of age with certain medical disabilities are eligible to receive Medicare, the association between FI and contact with a MHP may only be among food-insecure participants with other comorbidities who already receive medical treatment for other conditions. Third, the question in NHANES asking if participants saw a MHP in the prior 12 months did not assess where or in what context this visit occurred (e.g. office setting, emergency department, or hospital). Patients with FI have been found to have higher rates of acute healthcare utilization with more frequent emergency department visits and hospitalizations $[9,10]$. Food-insecure participants may have seen a MHP during these acute visits rather than in an ambulatory setting. Further research is needed to confirm our findings, though, and determine the potential reasons why food insecure individuals may be more likely to report seeing a MHP.
FI is an issue that affects a large proportion of households in the U.S. and is linked to depression, anxiety, and other mental health problems [5, 6, 32, 33]. Mental health problems may actually be one of the primary pathways through which FI leads to worse physical health outcomes, such as cardiovascular disease and cardiovascular risk factors [34]. As a growing number of national healthcare organizations are interested in mitigating the negative health effects of FI and other unmet social needs, understanding the complex relationship between FI and health could further tailor interventions for clinical care settings [25-27]. Although healthcarebased FI interventions have shown success in connecting patients to resources in the community, there is still limited data on if these interventions ultimately improve health outcomes [29]. These interventions have primarily focused on providing food resources to individuals with FI [28, 29], perhaps future interventions could focus simultaneously on lack of food and poor mental health to address FI and the accompanying sequelae.

MHPs have historically produced a large body of research on how social determinants of health affect the development and treatment of mental illness. However, expanding the role of the MHP to assess unmet social needs is an emerging area in the literature. ShieldsZeeman, Lewis and Gottlieb, describe an approach for directly addressing social determinants of health within the field of Psychiatry [35]. First, MHPs routinely elicit extensive social histories, so the evaluation of FI could be easily integrated into the psychiatric or psychological exam in a standardized manner. Brief 1 or 2-item FI questionnaires are available and have been validated in clinical care settings [36]. Second, MHPs often work in multidisciplinary settings alongside case managers, social workers, and other health professionals who are equipped to connect patients with health system, community, or government resources. Future studies could focus on developing and testing tools to address FI in mental health clinics.

Previous studies have suggested that providers may be less inclined to screen for social determinants of health if they are not aware of resources or perceive the resources available as insufficient [31]. In order to support FI screening by MHPs, it is critical that MHPs are informed of the government and community resources available to individuals with unmet social needs or are connected with social workers or other members of the care team who are familiar with the resources to which patients should be referred. In the U.S., this includes knowledge of SNAP, WIC, and local emergency food sources.

There are several limitations to this study that should be acknowledged. First, this study was cross-sectional, so we are unable to determine causation. Whether 
individuals who are food insecure are more likely to have been seen by a MHP or individuals who have been seen by a MHP are more likely to report FI is unclear. In either case, mental health clinics may be missing an opportunity to identify and address patients' unmet food needs. Second, this study extrapolates the diagnosis of MDD from responses to the PHQ-9, which is intended to be a screening rather than a diagnostic tool. Areas for future study include assessing the association between FI and other mental illnesses such as schizophrenia or bipolar disorder, which may have a more prominent impact on food security. Third, having been seen by a MHP was based on self-report. Also, the question used to assess if a participant had seen a MHP asked if participants had seen a psychiatrist, psychologist, psychiatric nurse, or clinical social worker, rather than evaluating each provider individually. Future studies should consider evaluating more direct measures of mental healthcare use and provider type, such as administrative data. Fourth, a priori we hypothesized that depression would be a potential effect modifier between FI and contact with a MHP. We did not find a significant interaction term, so we treated MDD as a confounder. Future studies should evaluate if the relationship between FI and mental healthcare utilization varies by depression severity or mental health diagnosis.

\section{Conclusion}

FI and depression are prevalent conditions that often occur concomitantly. In this nationally representative sample of adults in the U.S., we found that individuals with FI were significantly more likely to have had contact with a MHP in the prior year than individuals without FI, controlling for depression. Given the detailed social histories that MHPs elicit, the extended clinic visits they conduct, and the close relationships they form with patients, MHPs may be an important area to expand clinical social prescribing programs to assess and address patients' unmet food needs.

\section{Acknowledgements}

Not applicable.

\section{Authors' contributions}

Dr. Burrus, Dr. Girgis, Dr. Green, Ms. Lu, and Dr. Palakshappa all contributed to the study conception and design. Data analysis was performed by Deepak Palakshappa and Lingyi Lu. The first draft on the manuscript was written by Nina Burruss. Dr. Girgis, Dr. Green, Ms. Lu, and Dr. Palakshappa commented on previous versions of the manuscript. All authors read and approved the final manuscript

\section{Funding}

Dr. Palakshappa is supported by the National Heart, Lung, and Blood Institute of the National Institutes of Health under Award Number K23HL146902. The content is solely the responsibility of the authors and does not necessarily represent the official views of the National Institutes of Health.

\section{Availability of data and materials}

This study utilized publically available data from the National Health and Nutrition Examination Survey. This data can be accessed using the following link: https://www.cdc.gov/nchs/nhanes/index.htm

\section{Declarations}

\section{Ethics approval and consent to participate}

The Wake Forest School of Medicine Institutional Review Board deemed this study of publically available, de-identified data exempt from human subjects research.

\section{Consent for publication}

Not applicable.

\section{Competing interests}

The authors declare that there are no conflicts of interest.

\section{Author details}

${ }^{1}$ Wake Forest School of Medicine, Winston-Salem, NC, USA. ${ }^{2}$ Present address: Department of Psychiatry, University of North Carolina Hospitals, Chapel Hill, NC, USA. ${ }^{3}$ Departments of Internal Medicine and Pediatrics, Vanderbilt School of Medicine, Nashville, TN, USA. ${ }^{4}$ Department of Psychiatry and Behavioral Medicine, Wake Forest School of Medicine, Winston-Salem, NC, USA. ${ }^{5}$ Division of Public Health Sciences, Wake Forest School of Medicine, Winston-Salem, NC, USA. ${ }^{6}$ Departments of Internal Medicine and Pediatrics, Wake Forest School of Medicine, Medical Center Blvd, Winston-Salem, NC 27157, USA

Received: 19 November 2020 Accepted: 6 April 2021

Published online: 19 April 2021

\section{References}

1. Promotion OoDPaH. Social determinants of health. Healthy People. 2020; 2015.

2. Coleman-Jensen A, Rabbit MP, Gregory CA, Singh A. In: US Department of Agriculture ERS, editor. Household Food Insecurity in the United States in 2018, ERR-270; 2019

3. Compton MT, Shim RS. The social Determants of mental health. Focus. 2015;13(4):419-25. https://doi.org/10.1176/appi.focus.20150017.

4. Jones AD. Food insecurity and mental health status: a global analysis of 149 countries. Am J Prev Med. 2017;53(2):264-73. https://doi.org/10.1016/j.a mepre.2017.04.008.

5. Montgomery J, Lu J, Ratliff S, Mezuk B. Food insecurity and depression among adults with diabetes: results from the National Health and nutrition examination survey (NHANES). Diabetes Educ. 2017;43(3):260-71. https://doi. org/10.1177/0145721717699890.

6. Pryor L, Lioret S, van der Waerden J, Fombonne É, Falissard B, Melchior M. Food insecurity and mental health problems among a community sample of young adults. Soc Psychiatry Psychiatr Epidemiol. 2016;51(8):1073-81. https://doi.org/10.1007/s00127-016-1249-9.

7. Huddleston-Casas C, Charnigo R, Simmons LA. Food insecurity and maternal depression in rural, low-income families: a longitudinal investigation. Public Health Nutr. 2009;12(8):1133-40. https://doi.org/10.1017/S1368980008003 650.

8. Leung CW, Epel ES, Willett WC, Rimm EB, Laraia BA. Household food insecurity is positively associated with depression among low-income supplemental nutrition assistance program participants and income-eligible nonparticipants. J Nutr. 2015;145(3):622-7. https://doi.org/10.3945/jn.114.1 99414.

9. Kushel MB, Gupta R, Gee L, Haas JS. Housing instability and food insecurity as barriers to health care among low-income Americans. J Gen Intern Med. 2006:21(1):71-7. https://doi.org/10.1111/j.1525-1497.2005.00278.x.

10. Berkowitz SA, Seligman HK, Meigs JB, Basu S. Food insecurity, healthcare utilization, and high cost: a longitudinal cohort study. Am J Manag Care. 2018;24(9):399-404.

11. Berkowitz SA, Basu S, Meigs JB, Seligman HK. Food insecurity and health care expenditures in the United States, 2011-2013. Health Serv Res. 2018; 53(3):1600-20. https://doi.org/10.1111/1475-6773.12730.

12. Abar B, Holub A, Lee J, DeRienzo V, Nobay F. Depression and anxiety among emergency department patients: utilization and barriers to care. 
Acad Emerg Med Off J Soc Acad Emerg Med. 2017;24(10):1286-9. https:// doi.org/10.1111/acem.13261.

13. Tarasuk V, Cheng J, Gundersen C, de Oliveira C, Kurdyak P. The relation between food insecurity and mental health care service utilization in Ontario. Can J Psychiatry. 2018;63(8):557-69. https://doi.org/10.1177/0706743 717752879 .

14. About the National Health and Nutrition Examination Survey. https://www. cdc.gov/nchs/nhanes/about_nhanes.htm. Accessed 18 Nov 2020.

15. Hamilton WL, Cook JT, Thompson WW, Buron LF, Frongillo EA, Olson CM, et al. Household Food Security in the United States in 1995: Summary report of the food security measurement project: US Department of Agriculture, Food and Consumer Service; 1997. Accessed 18 Nov 2020

16. Fryar C, Carroll MD, Ogden CL. Prevalence of overweight, obesity and extreme obesity among adults: United States, trends 1960-1962 through 2015-2016: National Center for Health Statistics; 2018. Accessed 18 Nov 2020.

17. Palakshappa D, Speiser JL, Rosenthal GE, Vitolins MZ. Food insecurity is associated with an increased prevalence of comorbid medical conditions in obese adults: NHANES 2007-2014. J Gen Intern Med. 2019;34(8):1486-93. https://doi.org/10.1007/s1 1606-019-05081-9.

18. Berkowitz SA, Berkowitz TSZ, Meigs JB, Wexler DJ. Trends in food insecurity for adults with cardiometabolic disease in the United States: 2005-2012. PLoS One. 2017;12(6):e0179172. https://doi.org/10.1371/journal.pone.0179172.

19. Berkowitz SA, Baggett TP, Wexler DJ, Huskey KW, Wee CC. Food insecurity and metabolic control among U.S. adults with diabetes. Diabetes Care. 36(10):3093-9. https://doi.org/10.2337/dc13-0570.

20. Kroenke K, Spitzer RL, Williams JB. The PHQ-9: validity of a brief depression severity measure. J Gen Intern Med. 2001;16(9):606-13. https://doi.org/10.1 046/j.1525-1497.2001.016009606.X.

21. Patel JS, Oh Y, Rand KL, Wu W, Cyders MA, Kroenke K, et al. Measurement invariance of the patient health questionnaire-9 (PHQ-9) depression screener in U.S. adults across sex, race/ethnicity, and education level: NHAN ES 2005-2016. Depress Anxiety. 2019;36(9):813-23. https://doi.org/10.1002/ da.22940.

22. Adler NE, Stewart J. Health disparities across the lifespan: meaning, methods, and mechanisms. Ann N Y Acad Sci. 2010;1186(1):5-23. https:// doi.org/10.1111/j.1749-6632.2009.05337.x.

23. Schroeder SA. Shattuck lecture. We can do better-improving the health of the American people. N Engl J Med. 2007;357(12):1221-8. https://doi.org/1 0.1056/NEJMsa073350

24. Alderwick H, Gottlieb LM. Meanings and misunderstandings: a social determinants of health lexicon for health care systems. Milbank Q. 2019; 97(2):407-19. https://doi.org/10.1111/1468-0009.12390.

25. Daniel H, Bornstein SS, Kane GC. Addressing social determinants to improve patient care and promote health equity: an American College of Physicians Position Paper. Ann Intern Med. 2018;168(8):577-8. https://doi.org/10.7326/ M17-2441.

26. Council On Community P. Poverty and Child Health in the United States. Pediatrics. 2016;137(4):e20160339.

27. Committee on the Recommended Social and Behavioral Domains and Measures for Electronic Health Records. Capturing Social and Behavioral Domains in Electronic Health Records: Phase 1. Washington DC: 2014 by the National Academy of Sciences; 2014.

28. Alderwick HAJ, Gottlieb LM, Fichtenberg CM, Adler NE. Social prescribing in the U.S. and England: emerging interventions to address Patients' social needs. Am J Prev Med. 2018;54(5):715-8. https://doi.org/10.1016/j.amepre.2 018.01.039.

29. De Marchis EH, Torres JM, Benesch T, Fichtenberg C, Allen IE, Whitaker EM, et al. Interventions addressing food insecurity in health care settings: a systematic review. Ann Fam Med. 2019;17(5):436-47. https://doi.org/10.13 70/afm.2412.

30. Phipps EJ, Singletary SB, Cooblall CA, Hares HD, Braitman LE. Food insecurity in patients with high hospital utilization. Popul Health Manag. 2016;19(6): 414-20. https://doi.org/10.1089/pop.2015.0127.

31. Torres JM, Lawlor J, Colvin JD, Sills MR, Bettenhausen JL, Davidson A, et al. ICD social codes: an underutilized resource for tracking social needs. Med Care. 2017;55(9):810-6. https://doi.org/10.1097/MLR.0000000000000764.

32. Whitaker RC, Phillips SM, Orzol SM. Food insecurity and the risks of depression and anxiety in mothers and behavior problems in their preschool-aged children. Pediatrics. 2006;1 18(3):e859-68. https://doi.org/10.1 542/peds.2006-0239.
33. Kollannoor-Samuel G, Wagner J, Damio G, Segura-Pérez S, Chhabra J, VegaLópez $\mathrm{S}$, et al. Social support modifies the association between household food insecurity and depression among Latinos with uncontrolled type 2 diabetes. J Immigr Minor Health. 2011;13(6):982-9. https://doi.org/10.1007/s1 0903-011-9499-9.

34. Weiser SD, Palar K, Hatcher A, Young S, Frongillo E, Laraia B. Food Insecurity and Health: A Conceptual Framework. In: Food Insecurity and Public Health; 2015. p. 23-50.

35. Shields-Zeeman L, Lewis C, Gottlieb L. Social and mental health care integration: the leading edge. JAMA Psychiatry. 2019;76(9):881-2. https://doi. org/10.1001/jamapsychiatry.2019.1148.

36. De Marchis EH, Torres JM, Fichtenberg C, Gottlieb LM. Identifying food insecurity in health care settings: a systematic scoping review of the evidence. Fam Commun Health. 2019;42(1):20-9. https://doi.org/10.1097/ FCH.0000000000000208.

\section{Publisher's Note}

Springer Nature remains neutral with regard to jurisdictional claims in published maps and institutional affiliations.

Ready to submit your research? Choose BMC and benefit from:

- fast, convenient online submission

- thorough peer review by experienced researchers in your field

- rapid publication on acceptance

- support for research data, including large and complex data types

- gold Open Access which fosters wider collaboration and increased citations

- maximum visibility for your research: over $100 \mathrm{M}$ website views per year

At BMC, research is always in progress.

Learn more biomedcentral.com/submissions 